\title{
"Keep your enemies closer"
}

Harold Turner

General Practitioner,

Pigspapilloma Campus Surgery, Dreamingwell, UK

Received 25 July 2011 Accepted 25 July 2011
In ancient times, representatives from the planet 'Pharma' were welcomed with open arms into primary care to discuss new potions and magical ideas to make the world a better place. Back then, in the beginning, there were gifts of value, and these were good. But soon dark forces came among us and removed these from our presence. The mood of the empire of primary care became low. In time, as primary care emerged from the darkness and rehabilitation of this traumatic experience there came another magical power to challenge its strength: a power that sent into the ether business-class flights, five-star hotels and educational meetings in luxurious surroundings. The future looked grim but worse was still to come. The sword of transparency would be awakened and with no care for human nature, or common sense for that matter, would strike from our being branded pens and Post-it ${ }^{\circledR}$ notes.

These dark powers had one goal, one purpose. To eliminate from the mind of primary care the seed of opportunistic influence. For it was believed that this seed was too easily cultivated and would mean that patients would not get the best treatment. This seed goes under the name of COI or, to address it by its full title, 'conflict of interest'.

This is all well and good, but if doctors can't be trusted to make independent, unbiased and uninfluenced health care decisions, if we are so morally and ethically inadequate, why on earth is it being suggested that those 'from the other side', namely secondary care doctors, are included in clinical commissioning groups. Talk about a conflict of interest. It's more a 'conflict of clinical knowledge under pressure' or 'cock-up'.

Today, using the power of shape-shifting, our pharma brothers-in-arms have returned and once again seek to re-ignite the glow of the COI seed. They will not be seen, but will work their power through the morally weaker beings of health care.
So, Mr Consultant Orthopaedic Surgeon, where do you think we should commission our hip replacements from? Oh, that's a tough one, general practitioner (GP) colleague and new best friend. I see it's a multiple-choice question. Let me think a moment. Well, my department is alright I suppose, but we do have one of the highest rates of postoperative complications, in fact, I think I received an e-mail today with the latest performance statistics, yes, here it is. Fantastic, I'm top of the charts! So I guess hip replacements should really be commissioned from us. Best to stick to whom you know, eh? Fancy that, top of the charts again! Can someone tell me what 'mortality figures' are?

One suggestion has been to include secondary care representatives from acute trusts far, far away, to eliminate the risk of local bias. Two obvious problems here, as I see it. One is that evil parasite, patient choice. If a patient is happy to travel a day and a half to a hospital they've never heard of in another dominion, then once again the secondary care representative from this other dimension is hardly going to disrespect their own unit. Two, I can barely get a secondary care doctor on the phone, yet I'm supposed to believe they will actually attend a commissioning group meeting when they themselves exist on another planet. This becomes even more far-fetched than the concept of "if our toys and games are taken away from us we're more likely to behave in a grown-up and responsible fashion".

Then there's me. Like many GPs I work in general practice and in a hospital clinic. So, am I to be barred from being a member of the commissioning group because I have a foot in both camps and therefore, as a double agent, cannot be trusted? I can see how this might be a problem, but on the flip side it really is a huge advantage, because the bottom line is that, unlike those whose allegiance is with one, and only one, at the end of the day - which hopefully won't be too late because I've got a meeting with a private provider later 
on, in a swanky hotel and spa, and I don't want to keep the car and driver they're sending for me waiting - I'm not bothered. Why? You may well ask. Because either way it's a win-win situation for me. And that's who matters: me, not the patients, me, the supreme healthbeing, me, me, me!
Competing interests None.

Provenance and peer review Commissioned, internally peer reviewed. 